\title{
Helicopter crashworthiness: a chronological review of water impact related research from 1982 to 2006
}

\author{
Kevin Hughes* \\ Research Officer, Crashworthiness, Impacts and Structural Mechanics Group \\ Cranfield University, Bedfordshire, United Kingdom \\ Email : k.hughes@cranfield.ac.uk \\ * - Corresponding author : Tel: +44 1234750111 x5172 \\ James Campbell \\ Senior Lecturer, Crashworthiness, Impacts and Structural Mechanics Group \\ Cranfield University, Bedfordshire, United Kingdom \\ Email :j.campbell@cranfield.ac.uk
}

\begin{abstract}
This paper discusses in detail the contributions made in the field of water impact from 1982 to 2006 and provides a summary of the major theoretical, experimental and numerical accomplishments, up to and including the latest present-day European programmes on helicopter water crashworthiness. A summary of the major findings is presented and their importance to the direction of water crashworthiness development is discussed, together with recommendations for future research.
\end{abstract}




\section{KEVIN HUGHES, JAMES CAMPBELL}

\section{Introduction}

This paper discusses in detail the contributions made in the field of water impact from 1986 to 2006 and provides a summary of the major theoretical, experimental and numerical accomplishments, up to and including the latest present-day European programmes on helicopter water crashworthiness.

A previous review of water impact related research can be found in Sneddon (Ref. 1), who describes the milestones of water impact related research since the introduction of Von Karman's initial paper in 1929 (Ref. 2), and includes the theoretical and experimental developments between 1929 and 1959, before concluding with a review of water impact related research on aerospace structures.

This paper extends significantly on Sneddon's review, by concentrating solely on helicopter water impact related research, by identifying additional papers and updating the literature review to include the latest research on helicopter crashworthiness, experimental campaigns and numerical methods development. These papers have been divided into the following areas and are presented chronologically. The reader may notice some slight duplication of references in this review due to the literature falling into one or more categories; 1) Ditchings / Crash investigations, 2) Component drop tests, 3) Full-scale drop tests, 4) Applications of numerical methods / methods development, 5) Latest developments.

\section{The Water Impact Environment: A Critical Design Scenario}

The specifications related to providing sufficient occupant (crew and troop) protection in the event of a military helicopter accident is provided through MIL- 
STD1290A (Ref. 3) and the Aircraft Crash Survival Design Guide (Refs. 4 through 8), which has been superseded by the Joint Service Specifications Guide in 1998 (Ref. 9). However, these regulations do not specify any certification requirements for a water impact case, as they deal primarily with hard and soft soil surfaces.

In the event of a hard surface impact, the structure is designed to absorb the impact energy through plastic collapse for metallic components, or through brittle fragmentation for composites. This sacrificial structure allows the loads experienced by the occupants to be reduced to survivable levels, which is achieved through the harmonious interaction between the landing gear, subfloor stroke, energy absorbing seat and the restraint system. During a hard surface impact, the outer skin plays no part in the energy absorption, as shown in Fig. 1a.

The water impact environment is a challenging design scenario for which a conventional metallic subfloor performs poorly in terms of transmitting the water pressure and absorbing energy. During a water impact, the main mechanisms for energy absorption are different to hard ground, as the dominant response is through the membrane and bending behavior of the skin, coupled with limited plastic collapse of the surrounding structure due to its high failure strength, shown schematically in Fig. 1 b. This response results in high forces and accelerations being passed into the airframe and typically leads to the distortion of the passenger floor, the jamming or loss of the doors, together with the possibility of skin failure. Failure of the skin in turn reduces the floatation capabilities of the airframe and exposes the internal structure to secondary damage caused by water ingress. A summary of the typical structural damage encountered during a helicopter impact on water is presented in table 1. 


\section{Ditchings / Crash Investigations}

During the 1980’s, data for Civilian helicopter accidents was limited, as the data was typically reviewed by separate agencies and the information was generally fragmented, making it difficult to identify potential design improvements, or amend existing regulations, as an envelope of survivability had yet to be defined.

This problem was first addressed in 1986 by Coltman (Ref. 10) who provided a historical review of civil helicopter accidents that occurred between 1974 and 1978, which was later followed by a review of United States of America (U.S.) Navy and Army accidents in the same year (Ref. 11). A multitude of crash scenarios were considered, along with the mechanism and level of injuries sustained, which led to subsequent safety recommendations. The use of a shoulder harness could eliminate most of the injuries for impacts with a high forward velocity component. Harnesses were later incorporated to replace conventional lap belts as they demonstrated significant benefits for both impacts on hard and water surfaces. Impacts on water with a forward velocity component typically absorb energy through water displacement. Restraining the occupants fully, minimises the possibility of flailing injuries and other trauma associated with lap belts. In addition, the authors of Reference 11 recommend the use of energy absorbing seats, a floatation system to promote a stable post crash attitude, as well as emergency lighting in the event of an impact in reduced or low light.

The subsequent design improvements recommended in Reference 11 were based upon accidents that occurred between 1974 and 1978. As the role of the helicopter

diversified, a recommendation was made to regularly review the current implemented systems in order to improve their functionality, or operation. This feedback was essential 
to the future development of helicopters, as it would see the flight envelope being extended outside roles initially considered.

In order to collate comprehensive information from an accident, the USA Army developed a methodology in 1986, where specialists in the field would collect their respective data, as discussed in Adams (Ref. 12). A communication structure would then be in place that would enable the information to be shared between different departments, allowing trade-offs to be performed on the level of crashworthiness that should be incorporated into new designs, by taking into account projected costs and estimates on the benefit in the reduction of fatalities.

In order to refine the data set, comprehensive USA studies were performed in 1993 for Naval helicopter water impacts by Wittlin (Ref. 13), Chen (Ref. 14) and Muller (Ref. 15), who examined helicopter water ditchings that occurred between 1982 and 1989. This study was performed in two phases, where Part I dealt with the analysis of the impact and post impact conditions (Ref. 14), and Part II provided an assessment of the structural response on occupant injury, approaches for alleviating injuries, together with an evaluation of current numerical techniques for modeling helicopter impacts onto water (Ref. 15).

The findings from Part I identified three impact conditions, as well as two possible post water impact scenarios, which were immediate and delayed overturn of the airframe. Careful consideration was given to personal and helicopter floatation capabilities, which were generally found to be inadequate. The two main hazards to occupant survivability reported by Chen (Ref. 14) were drowning and exposure, which identifies the need for 


\section{KEVIN HUGHES, JAMES CAMPBELL}

developing the post impact behavior, as well as improving the energy absorbed by the airframe.

Structural failure of the rotorcraft was not found to contribute significantly to the level of injury, as in most cases, the occupiable volumes satisfied the definition of survivable. The flotation equipment was found to be poor, as it was incapable of retaining the floatation, stability, or orientation of the airframe. Reference 15 discusses a variety of techniques recommended for alleviating injury, including better occupant restraint, delethalisation of interior, energy absorbing seats, together with improved performance and use of flotation equipment.

One of the more recent European Union reviews for helicopter impacts on water was performed as part of the CAST project, which is an acronym for the "Crashworthiness of Helicopters on Water: Design of Structures using Advanced Simulation Tools”. The original internal project report (not publically available) was performed by Agusta in 2001, who assessed civilian helicopter impacts between 1982 and 2000, which involved world-wide accident databases. This assessment led to the classification of four different impact cases, namely controlled and uncontrolled ditchings, vertical descents, and fly-ins, where the pilot has full-control and is unaware of the iminent impact. This initial Agusta review was extended by Hughes in 2005 (Ref 16), who considered the yearly distribution of accidents, the level of injury for partial and survivable impacts, the post impact response and the degree of structural failure. Reference 16 concludes that the level and nature of the injuries are extremely susceptible to a variety of factors, namely helicopter construction, internal configuration and impact kinematics. Efforts need to focus not only on improving the crashworthiness of the internal subfloor structure to accommodate 
both hard and water requirements, but also in the area of floatation, as providing a stable platform and attitude for as long as possible will clearly reduce the number of post impact fatalities for survivable accidents.

\section{Component Drop Tests}

One of the difficulties in designing for crashworthiness is the limited amount of sacrificial structure available to occupants involved in helicopter crashes, when compared to their fixed wing transport counterparts, which results in a continual drive to develop high performance energy absorbing materials and develop concepts to improve occupant survivability. To aid in the understanding of the failure mechanisms involved in a water impact, experimental studies, along with the application of numerical methods were used to good effect. This section will review the experimental and numerical studies performed related to subfloor sections.

One of the early experimental studies was reported by Cronkhite (Ref. 17) in 1982, where the NASA Langley Research Center performed an experimental investigation into the effectiveness of five subfloor concepts onto both ground and water surfaces by quantifying the energy absorbed. The different crashworthy concepts included corrugated beams and half shells, foam filled cylinders, notched corners and canted bulkheads and included a drop test on water. The results generated from this study were used for code validation in 2004, which will be discussed later in this review. In addition, Berry (Ref. 18) contributed to developing our understanding of how energy absorbing structures are affected by the type of impact surface.

The characterisation of a metallic subfloor structure subject to hard surface and water impacts was dealt comprehensively within the CAST project, where two similar sections 


\section{KEVIN HUGHES, JAMES CAMPBELL}

of subfloor were dropped as part of one experimental campaign. Comparison of test and simulation for an $8 \mathrm{~ms}^{-1}$ drop test of a subfloor section of a Westland WG-30 helicopter (aft passenger section) is reported in Ref. 19 by Pentecôte in 2002, in which simulation studies were performed using Pam-Crash, and reported in Ref. 20 by Hughes in which simulations were conducted using LS-DYNA3D in 2003.

The two metallic subfloor components were manufactured from a 2014 aluminium alloy, consisting of longerons that run along the longitudinal axis of the helicopter, that are reinforced with evenly spaced L-section stiffeners. The lower parts of the longerons are reinforced with Z-section stiffeners that run fully along their length, which are also directly riveted to these frames and lower skin. The curved longitudinal end-sections are connected directly to the main lift frames and provide a direct load path for the main engine and gearbox assemblies.

The frames orientated in the transverse direction are also manufactured from metallic sheet and are typically shorter in length. L-section brackets are riveted to the top part of these frames, which provides the transverse attachment points for the floor. These transverse frames are connected to the longerons via C-section overlaps to form individual box-sections. The transverse frames contain a cut out for a z-section stringer that runs along the mid-section span of the skin, in order to provide structural rigidity. The upper panels that form the passenger section are manufactured from Fibrelam, consisting of unidirectional glass fibres bonded to a honeycomb / aramid core. The lower metallic panels form the outer skin and are riveted directly to longitudinal and transverse frames. 
In references 19 and 20, a complete-section-by-section analysis was performed both quantitively and qualitatively with simulation results for the $8 \mathrm{~ms}^{-1}$ drop test performed at the water impact facility at CIRA, Italy. As shown in Fig. 2, the metallic floor retains its global integrity, as the main longitudinal frames remain intact. The belly skin deflects significantly in-between these frames, together with two locations of skin failure due to rivet pull out and material fracture. The curved end sections of the floor remain relatively undamaged, as their shape minimizes loading at these locations due to the redirection of the water surface. The dominant behavior of the skin in response to a water impact can be clearly seen in Fig. 2, where the skin deflects in between the main longitudinal frames.

References 19 and 20 provide a detailed understanding of the collapse mechanism for this type of loading, which is critical if design limitations and possible improvements are to be identified, such as improving the membrane response of the skin and improving the transmission of the water pressure into the subfloor beams and the increased collapse of frame and intersection joints. The recommendation for a dual role capability coincides with the conclusions reported by Vignjevic (Ref. 21) and Ubels (Ref. 22).

Improving the crushing behavior of the intersection joints is an area of active research as many authors have identified this limitation in relation to water impacts, due to the limited collapse that is observed. The redesign of the intersection elements was given consideration by Bisagni (Ref. 23) in 2002, where Pam-Crash was used to initially analyze an isolated element and then a complete metallic subfloor section in response to hard surface drop tests and horizontal sled loadings. Load-shortening diagrams were used to compute the peak load, average crush load, specific absorbed energy and the stroke and crush load efficiencies in order to assess the validity of the numerical 
approach. Consideration was given to rivet modeling, whereby beam elements with varying cross-sectional properties were defined. For a single intersection joint, the number of failed rivets was close to test, but visualization was difficult due to the large number of plastic folds that ensued. The author of Reference 23 performed an investigation into how rivet failure affects the loads and the resulting behavior by using the same numerical model with no failure defined. The results changed by a few percent, indicating that rivet strength was not a critical parameter. Due to the high level of correlation achieved, the author of Reference 23 could, with good confidence, consider the application of optimization techniques to improve the energy absorption capabilities of the present design.

Further consideration was given to characterising a subfloor response to hard surface and water impacts by Skinner (Ref. 24) in 2003, who investigated the effect of rivet failure on the structural response using the coupled DYNA3D FE-SPH capability developed at Cranfield. Skinner (Ref. 24) agrees with Bisagni (Ref. 23), as the global response appears to be relatively insensitive to rivet failure, although differences in the local collapse mechanism were reported.

In 2005, Hughes (Ref. 16) provides a comprehensive study of the crashworthiness of helicopters onto water and presents a comparison between test and simulation for the impact of a typical metallic subfloor section onto both hard surface and water (Fig. 3), together with a fully instrumented WG-30 helicopter drop test onto water (shown later in Fig. 4). The detailed quantitative and qualitative assessments for frame heights and the magnitudes for the deflection of the skin enabled an assessment of the validity of component and full-scale simulations with respect to one another, as well as identifying 
design changes that could potentially improve the level of crashworthiness currently offered.

\section{Composite Materials Research : Implications For Crashworthiness On Water}

As understanding of the failure mechanisms associated with impacts on water increased, it became clear that existing crashworthy components were inadequate, which forced engineers to consider redesigning the construction of the frames to promote collapse, as well as improving the membrane response of the skin. This change in thinking allowed engineers to assess different frame constructions from an energy absorbing point of view, as well as giving consideration to the type of materials used. Engineers turned towards the use of composite materials as a possible solution to the water impact problem.

The potential offered by the use of composites for a crash application can be traced back to 1980, where Pifko (Ref. 25) presented a combined automotive and aeronautical analysis using DYCAST (Dynamic Crash Analysis of Structures, Ref. 26), which compared the differences between a composite and a more traditional aluminum structure onto a hard surface. The composite construction demonstrated the benefits not only in reducing the forces transmitted to the occupants, but also the weight advantages that can be attained without compromising structural strength.

Due to the dominant membrane behavior of the skin, the skin is highly loaded, which can fail either diretly in the mateiral itself, or through a combination of material and rivet failure. This failure typically results in secondary damage caused by the ingress of water and the corresponding reduction in the floatation capabilities of the airframe. Increasing the membrane stiffness of the skin without failing was critical if the loads were to be 
transferred to other energy absorbing components of the design. Naturally, engineers turned to composite materials for this type of mechanical response, which led to the publication of the tensor skin concept in 1994 (Ref. 27). This concept was further developed by performing both static and dynamic tests of a single sine wave construction of a representative subfloor section in 1995 (Ref. 28). The results were encouraging from both studies, as the tensor skin demonstrated an ability to transfer the membrane loads and initiate crushing to other parts of the subfloor. This concept was extended by Delatombe (Ref. 29) in 1998, which involved validation against different box and cruciform structures.

The development of composite material models to predict inter and intra ply delamination and failure has led to significant development by academic and research institutions worldwide. A comprehensive review of composites was provided by Kindervater (Ref. 30) in 1997, in terms of their manufacturability, different types of trigger mechanisms that can be employed to initiate a crushing response, along with the validation of finite element techniques to predict their energy absorbing response. The literature contains numerous papers directly related to composite material model development and its application as an energy absorber, but this is beyond the scope of this paper, which focuses on the methods / techniques directly related to helicopter water related research. For further reading on composite model development, the reader is directed to reference 31 .

Sareen (Ref. 32) in 1999 provides a summary of the crash analysis of energy absorbing subfloors during ground and water impacts. To further develop the application of sine wave beams for longitudinal and lateral frames and to move away from traditional 
metallic panels, Vicente (Ref. 33) in 2000 assessed their applicability for impact onto hard and soft gravel surfaces using a carbon fiber composite. The composite model developed was based on a macroscopic approach to develop equivalent material properties, which required extensive tuning and a priori knowledge of the failure modes. Despite this limitation, the characterization of this type of frame construction and its potential for providing a progressive collapse front, overcomes the poor frame response observed with conventional metallic frames.

The application of the tensor skin was further demonstrated by McCarthy (Ref. 34) in 2000, where sine wave beams were used to promote controlled crushing, as well as tapered cruciform elements to provide lateral strength and an increasing collapse load. The floor specimen was dropped onto rigid ground and soft soil in order to characterize its response to two different impact surfaces, together with material calibration via quasistatic bulge tests. Further development work was required, as debonding / delamination effects were not captured with the current modeling approach, which would be problematic if water tests were performed. However, the results further demonstrated the potential benefits of this concept over conventional metallic skins.

Another area for improvement concerns the joints formed at the intersection between longitudinal and lateral frames. With a conventional metallic floor, the frames are directly connected via rivets. This type of construction reinforces these locations and hinders the progressive collapse of the frames, as higher collapse loads are now required. In order to develop a composite solution to this problem, a three year German / French research collaboration between ONERA and DLR was reported in 2000 by Delatombe (Ref. 35), who provides a summary of the research performed on carbon / aramid / epoxy 
laminates. In reference 35, Pam-Crash was used by DLR to recreate cylindrical crush specimens and the quasi-static and dynamic simulation of sub-floor box structures, consisting of longitudinal beams (sinewave, trapezoid and rib-stiffened), lateral bulkheads and cruciform intersection elements. Good agreement was obtained, although load levels and energy absorption were low due to over simplifications in the fabric model developed. The application of new cruciform intersection joints is particularly relevant to the development of water crashworthiness, as existing metallic designs do not use the available stroke efficiently.

This paper recognizes the significant contribution to the field of composite crashworthiness by Kindervater (Ref. 36), through detailed experimental campaigns, implementation of new composite material models to replicate fiber / matrix failure and interply delamination. The author of Reference 36 recognizes the importance of developing these types of models, which were extensively tested through bird strike on wing leading edges, sacrificial Carbon Fibre Reinforced Plastic (CFRP) fuselage components, as well the composite demonstrator developed as part of the CAST project (which will be discussed later in this paper).

\section{Applications Of Numerical Methods / Methods Development}

The solving of non-linear transient problems has led to the development of a broad range of numerical methods, such as Lagrangian, Arbitrary-Lagrangian-Eulerian, coupled FE-SPH (Finite Elements and Smooth Particle Hydrodynamics), together with hybrid approaches. The difference between these methods lies in the spatial discretisation used and the corresponding computational resources required, which allows a diverse range of 
applications to be numerically simulated. This section will describe the application and evolution of these computational methods for developing helicopter crashworthiness.

One of the earliest papers related to the crashworthiness of helicopters can be found in 1977 by Winter (Ref. 37), which is one of the first studies that employs numerical finite element analysis to predict the deformation of a skin covered aluminum frame impacting into a rigid barrier.

The use of the finite element technique as a potential design tool is evident from the number of papers produced during the 1990's, which demonstrate the versatility of this approach. For example, Vignjevic (Ref. 38) published a paper in 1997, which concerns the detailed analysis of a Lynx airframe impacting onto a rigid surface. The methodology adopted involved an iterative design process, whereby the code was used to optimize the thickness of the lift frame. This approach provided an insight into how a code can be validated against test and then used in a predictive manner in situations where experimental testing would be too costly.

Due to the limited computational capabilities at the time, many researchers were involved with the development of hybrid methods, such as DRI/KRASH (Ref. 39), which uses lumped masses and user-defined beams to represent a complex structure. This approach allows parametric investigations to be performed for a significantly reduced simulation time when compared to a finite element model. However, the costs associated with this method are the significant input and man-hour costs required in order to develop a tuned model.

Wittlin (Ref. 13) performed a survey of Naval helicopter water impacts in a study published in 1993, that employed a hybrid DRI/KRASH analysis. The authors of 
Reference 11 were able to employ the analytical simulation of the entire crash scenario during impact and post impact. The advantage of this type of analysis is the rapid evaluation of different impact conditions, for example, to determine the benefits from an extracted or retracted landing gear for various sea states.

The development of numerical methods to predict the response of composite energy absorbers for low speed impacts in transport aircraft was the focus of a $4^{\text {th }}$ European Union framework project to design for crash-survivability, CRASURV (Ref. 40). The project was launched in 1996 and was partially funded under the Aeronautics Area of the programme on Industrial and Materials Technology (BRITE / EURAM). Coupon tests and dynamic subfloor drop tests were performed in order to support the simulation activity, which led to the conclusion that deficiencies exist in modeling progressive failure of fabric composites. The literature generated from this research project will be discussed later in this paper.

Wittlin (Ref. 41) reports on the findings of using a combined numerical approach for the water impact of a Vertical Take-Off and Landing (VTOL) Osprey in 1997. The detailed finite element approach allowed the structural deformation to be modeled explicitly and could be used for final design verification, whereas a "simpler" DRI/KRASH model was also developed, which provided a global response of the structure and is better suited to concept development through parametric investigations. The idea of using these two codes in conjunction is now common practice (Ref. 42), as data can be mutually interchanged between codes for self-validation, in an effort to reduce the reliance on experimental testing. 
The need for developing a water methodology was discussed by Clarke (Ref. 43), as part of a joint Rotorcraft Industry Technology Association (RITA) research project in 1998. Here, the merits of an ALE approach are discussed to see whether this formulation was capable of recreating the pressures by incorporating a layer of air between water and structure. Many modeling issues were identified, such as correctly initializing the velocities for the structure and surrounding air particles by incorporating the free fall of the structure. There are also problems associated with the blending logic used to handle the transmission of the variables, which can also affect the accuracy of the solution. The ALE approach is computationally expensive when compared to other numerical methods and it has yet to be demonstrated whether incorporating this layer of air can significantly improve the accuracy of crash performance simulations.

The application of alternative approaches to water modeling was further demonstrated in 1999 by Ribet (Ref. 44), who explored Lagrangian and ALE options available within the commercial code RADIOSS. Both formulations have limitations to fluid modeling, as stability issues when simulating an extreme deformation event limit Lagrangian approaches, whereas the Eulerian part of ALE is better suited to predicting fluid flow, these methods suffer from blending logic and the associated difficulty of material tracking through the cells. These limitations made the author or Reference 43 conclude that developing a Lagrangian model (to capture structural response) with a fluid capability could provide optimum results. This view is shared by many researchers, which has led to the extensive development of a coupled FE-SPH capability to incorporate this recommendation. 
The ALE approach has demonstrated its potential by providing good agreement with Von Karman Theory for the magnitude of the pressures and accelerations for a conventional metallic subfloor structure impacting onto water, as reported by Vignjevic (Ref. 45) in 2001. Vignjevic identifies the importance of the water as a passive energy absorber, as the conventional design was predicted to absorb 55\% less energy when compared to a hard surface impact. In a subsequent paper published in 2002, Vignjevic (Ref. 21) demonstrates how an ALE approach was used as a predictive design tool, by validating a novel design concept that attempts to overcome the problem of high strength locations and the resulting high decelerations passed through the cabin floor to the occupant. A dual role capability floor was proposed, whereby the localized collapse strength of the joints could change, depending upon the type of surface encountered. The concept was validated numerically, but further research is required to develop this concept into a feasible solution.

In the same year, Vignjevic (Ref. 46) also presented a paper on the development of a repulsive contact treatment implemented within their SPH code, which was a necessary requirement in order to develop a coupled FE-SPH capability, which had the potential to extend the capabilities of existing numerical techniques.

The contribution by Fasanella (Ref. 47) to the field of water impact was published in 2003, through testing of a composite aircraft fuselage section, described by Jackson (Ref. 48), that was dropped at $25 \mathrm{ft} \mathrm{s}^{-1}$ onto water for the purpose of direct comparison with prior drop tests onto hard surface and soft soil. The subfloor of the fuselage section consisted of five uniformly spaced Rohacell foam blocks overlaid with E-glass/epoxy face sheets; its construction similar to a conventional metallic box-section and skin 
structure. The experimental drop test was supported by numerical simulation using the "fast" fluid-structure coupling within MSc DYTRAN and ALE and SPH formulations available within LS-DYNA3D. The authors of Reference 47 provide extremely practical modeling recommendations for all three approaches, along with their limitations. The damage observed was consistent with current understanding with multiple failures of the fiberglass face sheets, due to high in-plane membrane strains generated as the skin deflects in between the Rohacell frames, which show no evidence of collapse. The authors (Ref. 47) conclude that a coupled Lagrangian FE and SPH approach showed the best agreement with test, although further modifications were needed in refining the material properties for the fiberglass skin, as the predicted damage was more severe than test.

Another American study was published in 2003 by Randhawa (Ref. 49), whose aim was to investigate the application of numerical techniques to impacts on water, through low speed spherical projectiles and the recreation of the UH-1H drop test performed by Wittlin in 2000 (Ref. 50). Reasonable agreement for the spherical drop tests were performed with Lagrangian and ALE formulations. ALE was used to predict the accelerations levels, which were applied as an impulse to two different seat models in MADYMO (Ref 51). The analysis demonstrated how the lumbar loads could be reduced through careful seat design. The development of a coupled local and global approach is gaining increasing popularity as a virtual testing approach, especially as numerical codes become more capable and robust.

The previously discussed experimental campaign performed under the European Union CAST project was novel, in that it was the first time that the same passenger floor 
construction would be subject to two extreme types of loading in one experimental program. Another objective of CAST involved the development of predictive numerical methods that could assist helicopter manufacturers in a Virtual testing environment.

The component floors dropped onto both hard and water surfaces were studied numerically and published by Pentecôte and Kohlgrüber using Pam-Crash (Ref. 52 and 53) in 2003 and 2004 respectively. In parallel, Hughes in 2003 (Ref. 20) performed the same simulations using LS-DYNA3D (Fig. 3), which allowed independent assessments to be made of two commercial codes, with a view for numerical methods development.

A coupled FE-SPH approach to fluid-structure interaction was also presented by De Vuyst (Ref. 54) also as part of the CAST project, together with a paper discussing the application of the finite element approach to water impact by Kohlgrüber (Ref. 55), and Zorz (Ref. 42), who provided a comparison between full-scale WG-30 drop test and simulation using DRI/KRASH.

In 2005, this work was extended by Hughes (Ref. 16) who discusses the problems associated with a Lagrangian approach to water modeling through the application of rigid shapes impacting onto water. Alternative techniques to water modeling are also presented in an attempt to minimize the stability problems that arise between fluid and structure boundaries. A methodology is presented in Reference 20 concerning the simulation of fluid-structure interaction problems within the SAFESA approach (SAFE Structural Analysis - Vignjevic (Ref. 56)), in identifying idealization, procedural and formulation errors, along with techniques and recommended practices to minimize their effects. Reference 16 concludes with applying the validated simulation tools to investigate a potential solution for improving the crashworthy response by developing a 
multiple cell configuration that attempts to maximize skin deflection and the passive energy absorbed through the water.

Hughes (Ref. 16) also discusses modeling guidelines on applying a purely Lagrangian approach to modeling water, as well as providing discussion on the areas of good and poor agreement. A purely Lagrangian approach was chosen, as it represents the "lowest" computational cost over other methods including ALE and SPH and would be better suited to capturing the structural response, as initially, inertial forces dominate over viscous forces. The use of this approach would allow code limitations to be identified (which was the aim of this research), which could be refined at a later stage, if more complicated numerical methods were required.

Difficulties encountered with a purely Lagrangian approach concern the pressure time histories, due to a difference in dynamic impedance between simulation and test, as the simulation only modeled water-structure, as opposed to water-air-structure that occurs in reality. Therefore, the cushioning effect this layer of air has on the pressures could not be investigated. The situation is further compounded by contact instabilities that develop in the water elements, together with limitations in the material model (no cavitation, etc) used to represent water. These problems occurred when applying a purely Lagrangian approach to water modeling and its implication on virtual testing were reported by Hughes (Ref. 57) in 2006.

The difficulties of existing numerical water models to predict the water pressure can result in spurious results, including negative pressures. Due to the penalty nature of the contact algorithms used, this approach can lead to separation between water and structural finite elements, together with dynamic impedance issues between test and 
simulation. This issue raises questions concerning the accuracy of the structural response predicted, due to errors in the pressure loads generated. Zardoni (Ref. 58) in 2005 attempts to develop a simple cavitation model within DYNA3D to incorporate some of the main features of cavitation, namely the introduction of a minimum pressure threshold that prevents the pressures from becoming negative and the introduction of air/liquid properties in the regions of cavitation formation. Experimental data was generated by dropping an aluminum box at various impact velocities, which was instrumented with strain gauges.

Existing methods use a simple cut-off pressure, which prevents the pressure from going lower than a user-defined threshold, which can yield acceptable results for certain applications. However, when cavitation is present, this model is not accurate enough. The proposed cavitation model was based upon a step-by-step vapour pressure calculation using Antoine's equation and is widely used in engineering applications. The equations for density and speed of sound in the air/water mixture employ a void fraction calculation that is dependent upon the bubble growth velocity, which make it possible to take into account fluid property changes. While some improvement was noted, this topic remains a current area of research.

The trends in numerical simulation related to aircraft structures under crash and high velocity impact are discussed by Kindervater (Ref. 36) in 2005, who provides a summary of how explicit codes have been used to support concept, design and certification. The paper provides an overview of helicopter crashworthiness to impacts on water, with strong reference to the outcomes of the CAST project. Significant research has been provided by Kindervater on the development of composite energy absorbing structural 
crashworthiness concepts. Kindervater also discusses the crashworthiness of an A320 fuselage section impacting onto a rigid surface, as well as the ditching of transport aircraft on water. Fly-in impacts require significant computational resources and a coupled FE-SPH code to perform this type of analysis. The influences of cavitation, suction forces and the cushion effect the layer of air has between structure and the water surface is highlighted by Kindervater, who recommends the use of SPH particles to represent air.

\section{Full-Scale Testing}

A full-scale airframe drop test onto water was reported by Candy (Ref. 59) in 2000, where the application of a purely Lagrangian approach was applied to recreate the helicopter accident at the Brent Spar oil platform in 1990 (Ref. 60). In addition, separate simulations were performed using Lagrangian and coupled Eulerian-Lagrangian approaches to recreate a fly-in impact of the space shuttle (Ref. 60). The comparisons revealed a useful insight into both approaches, which led to the conclusion that a purely Lagrangian approach demonstrated its potential as a cost effective design tool in recreating a vertical water impact, whereas the coupled formulation suffered from numerical noise and divergence in the response due to a limited water model that did not include buoyancy effects.

Prior to the 1990's, the US dominated the research in the field of crashworthiness onto water. The first European coordinated research came in 1993 entitled “Crashworthiness for Commercial Aircraft”, which was a $3^{\text {rd }}$ European Union framework program, whose aim was to increase safety in moderate commercial aircraft crashes (Ref. 61). This program led to increased European Union knowledge in this field and allowed 
Europeans to play a stronger role in informing the Civilian regulatory bodies of their findings and recommendations, with a view for advising in the development of crashworthiness guidelines. The project achieved many milestones, including the development of new non-linear capabilities in the form of improved material models for energy absorption.

HELISAFE (Ref. 62) was introduced in 2000 and was a $5^{\text {th }}$ Framework European Union research programme, whose aim was to improve the survivability of occupants in helicopter crashes through the use of an advanced safety system concept, which was based upon interacting safety features. HELISAFE developed a simulation tool (HOSS) that was capable of predicting the response loads on the human body by taking into account the interaction of passive safety features. Sled tests were performed using crash test dummies that enabled parametric studies to be performed, which led to the development of new proposals for certification procedures and the increased use of crash test dummies in subsequent experimental programmes.

Recent European projects in aeronautical crashworthiness are typically through collaborative projects, whereby increased emphasis is placed upon the pooling of specialist organizations and experimental expertise. These combined efforts are more favorable in attracting funding due to the cross fertilization of ideas, which in turn, leads to an increase in the number of full-scale experimental test programmes in order to enhance current understanding.

One of the first documented full-scale tests was performed in 1999 by Fasanella (Ref. 63), whereby a composite helicopter was dropped onto a rigid surface. The experimental data was used to validate the composite modeling capabilities of MSC DYTRAN. A 
two-stage process was used, whereby the output from a detailed landing gear model was used to provide the initial conditions for a detailed fuselage model. This approach provided a high level of agreement for the accelerations, the sub-floor crushing response and time sequence of deformation, providing confidence in the use of a finite element approach as a crashworthy design tool.

The caveats associated with performing full-scale drop tests were highlighted in the same year, where the difficulties associated with assessing the validity of numerical results by direct comparison to test for a $\mathrm{UH}-1 \mathrm{H}$ impact onto water, were discussed for both FE and hybrid approaches by Wittlin (Ref. 41 and 50). Problems arise due to the large amount of scatter with the experimental results, especially for the pressures, as neither code was able to produce satisfactory results. This issue led the authors of Reference 41 to conclude that absolute agreement to test should not be used as a validation criterion and also raised the issue that a window of correlation is required.

The latest European Union funded research into helicopter crashworthiness was implemented in 2000 with the CAST project (Ref. 64). This program served to enhance current understanding of water impacts through a series of dedicated experimental component and full-scale tests. This project involved assessing current commercial finite element codes for their applicability to water modeling, together with the recommendations for future numerical tools development. This modeling effort led to the development of a coupled Lagrangian FE-SPH capability, as discussed by De Vuyst (Ref. 65) in 2003. One of the outcomes of the project was the development of composite and metallic technology demonstrators that offered improved energy absorbing capabilities for an impact on water. 
Another European Union Framework V research project was introduced in 2001 (Ref. 66), whose aim was to develop methods and tools to predict the " $\underline{C R A}$ sh behavior of

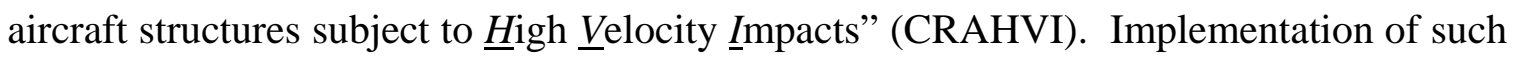
methods will contribute to enhancing safety through damage tolerant craft and the development of crashworthy aircraft concepts. The impact conditions considered were bird-strike on wing leading edges, debris hits (tire and engine parts), hailstones on composite structures and fuselage impacts with water, sloped terrain and ground-based obstacles. The state of the art analysis techniques were validated against a series of impact tests, which led to numerical tools development and refinement.

Other notable simulation efforts include a summary of rigid surface and water impacts of a low fidelity WG-30 helicopter model (Ref. 67) in 2001. Their aim was to assess current simulation tools, which found that a purely Eulerian approach was incapable of capturing the fluid-structure interaction. What is interesting about this paper is the use of a coarse WG-30 6,000 element model to assess the damage to the floatation system and surrounding structure (which was developed significantly by Hughes (Ref. 16), to incorporate over 360K elements as part of the CAST project (Fig 4.). However, the level of detail in the undercarriage made it difficult to perform a detailed analysis, as it allowed only the identification of potential problem areas, but the author of Reference 67 recommends increasing the crumple zones in the structure in order to retain the buoyancy of the helicopter.

Significant contribution to the field of helicopter crashworthiness research has been provided by Fasanella and Jackson (Ref. 68 through 75), who have not only provided evidence to assess the injury potential for occupants during full-scale hard surface drop 
tests of composite rotorcraft and fuselage sections, but have also provided extensive guidelines on best practices for crash modeling and simulation (Ref. 76).

In 2002, Vigliotti (Ref. 77) presents the experimental campaign of an $8 \mathrm{~ms}^{-1}$ water drop test of a complete WG-30 airframe as part of the CAST project. The airframe fuselage overturns a few seconds after impact, which was fully instrumented with accelerometers, pressure transducers and an anthropomorphic test dummy. In 2003, Pentecôte (Ref. 52) discusses the application of Pam-Crash to this drop test and provides a quantitative comparison between test and simulation for the pressures, accelerations and main features of deformation obtained using a Lagrangian water representation. The calculated and observed deformations of the structure correlated well, although the simulation results were conservative when compared to test. Pentecôte also reported the difficulty in comparing pressure time histories, as little agreement was obtained for the initial peak load, which was overestimated by the code.

\section{Latest Developments}

Previous attempts at improving the crashworthiness of rotorcraft have revolved around developing a new design, which is a costly approach, but does allow more flexibility to overcome any inherent limitations with existing designs. The applications of retrofit solutions are starting to be developed. The development of a cost effective solution that can be applied across the entire helicopter fleet is preferable. One example of a retrofit solution is the composite fuselage section, reported by Jackson (Ref. 48), where a composite foam subfloor was designed to limit the loads transmitted to the occupants and to provide a stable floor for reacting crush loads during hard surface 
impacts. The same fuselage section was evaluated for soft soil and water impact, as reported in Ref. 47.

In order to address current limitations with conventional metallic subfloor structures, Kohlgrüber (Ref. 53), presented in 2004, a summary of the latest composite subfloor design that represents the culmination of research and development during the European CAST project. The proposed design consists of a novel approach to avoiding skin rupture during an impact on water, as well as crashworthy components specifically incorporated to provide an improved response during a hard surface impact.

A novel composite skin was developed that consists of a flexible outer skin constructed from aramid fibers, which is stiffened by a Rohacell foam layer (Fig. 5). A further layer of aramid is glued to form the inside surface of the skin.

This concept absorbs the impact energy through the delamination of the Rohacell foam layer from the outer composite skin, which in turn leads to a reduced bending stiffness and allows higher membrane forces to develop in the skin. The reduction in bending stiffness and the fact that the skin retains its integrity allows the water loads to be transferred to carbon bulkheads and the longitudinal beams that contribute to energy absorption through controlled crushing. In addition, carbon / aramid crush cones are incorporated at the joints of the frames to provide increased energy absorption during a hard surface impact.

The authors of Reference 53 provide an overview of the extensive testing and numerical simulation performed using Pam-Crash, which provided good correlation with respect to the observed damage. The same authors extended this simulation work by varying the impact conditions to include pitch and roll, where they were able to 
demonstrate that the proposed new configuration worked well for all impact conditions considered, as shown in Fig. 6. The skin concept allows large deformations without failing, providing further confidence with the proposed solution to improving crashworthiness on water.

This composite subfloor concept was also analyzed by Perez-garijo (Ref. 78), who performed a survey of existing composite damage models within DYNA3D and implemented a modified fabric damage model that allowed for the post failure degradation of the elastic properties resulting from damage. Test-analysis correlation also revealed the same failure modes as noted by Kohlgrüber (Ref. 53), with good agreement for the locations of failure and the global response of the structure. However, the acceleration levels were consistently lower than was observed experimentally.

The development of metallic subfloor concepts for improved crashworthy response onto hard and water surfaces was studied by Tho (Ref. 79) in 2004, which involved the assessment of cylindrical foam filled and corrugated half-shell concepts using ALE and SPH formulations within LS-DYN3D. The numerical results were validated against drop tests performed during the 1980's by Cronkhite (Ref. 17), where five different energy absorbing subfloor concepts were investigated under a NASA contract. Sensitivity studies were performed, which included varying the model parameters and impact angles, until an acceptable level of correlation was achieved.

For the water analysis, only one drop test was performed, where the foam was removed from the cylindrical concept, as reported by Berry (Ref. 18), who correlated the numerical analyses for this impact condition, and then used the code to predict the effectiveness of the two different metallic concepts. For all simulations, the magnitude of 
the peak acceleration, pulse shape and duration were compared, as well as providing a component breakdown for the energy absorbed.

The authors of Reference 18 conclude that the presence of foam can stabilize energy attenuation for a hard surface impact, but little benefit was gained in terms of energy absorption for a water impact. For both concepts, the structures absorb much less energy when compared to the hard surface counterpart. However, the authors (Ref. 18) recommend that the analysis methodology developed could be used to evaluate and quantify multi-terrain impacts in order to improve and evaluate their crashworthy responses.

The application of optimization techniques to the field of crashworthiness is becoming increasingly common, especially for composite and honeycomb structures. In 2004, Lanzi (Ref. 80) discussed the application of neural networks to reproduce the crash response of structural components ranging from cylindrical riveted tubes, honeycomb structures and a helicopter subfloor structure. Despite the fact that only hard surface impacts were considered, the ideas generated demonstrate the potential of using parallel subsystems of small neural networks, with a view for developing robust and flexible optimization tools. The key to success lies with the training of the neural networks, where Lanzi uses Pam-Crash to provide the necessary data points. The results from the optimization process for the maximum and mean forces and the force-time curves agree within $10 \%$ of test, demonstrating the usefulness of this fast reanalysis methodology. This method has merit during the preliminary design phases in identifying promising configurations, which will have far reaching implications for all areas of crash protection. 
Recent advances in the development of helicopter crashworthiness for impacts on water are discussed by Vignjevic in 2006 at the European Rotorcraft Forum (Ref. 81). The authors of Reference 81 provide an overview of the research and development during the last six years at Cranfield University, which has seen the development of new metallic and composite damage models within DYNA3D, together with an algorithm for coupling FE and SPH, as discussed by De Vuyst (Ref. 82) in 2005. Reference 79 also discussed the recent development of an adaptive SPH capability, which significantly extends the boundaries in application to processes that involve extreme deformation, which will have a significant impact on safety, impact and crash evaluation studies performed on water within a coupled Lagrangian framework. The authors of Reference 81 conclude that the development of a coupled FE-SPH capability has opened up the possibility of performing detailed post-impact survivability studies, as investigating the stability issues for a variety of sea-state conditions, may lead to design changes that can prolong a stable attitude and increase survivability due to exposure / drowning hazards. In 2006, Vignjevic extended this work by publishing a paper on an improved contact algorithm for meshless methods (Ref. 83).

One of the latest papers was published by Taher (Ref. 84) in 2006, who proposes a new composite energy absorbing system for retrofit to aircraft and helicopters, which utilizes a lightweight composite energy absorbing keel-beam consisting of an inverting stringer. With this design, the stringer guides the collapse failure mechanism of the frame by forcing it into a circular groove, so that the crush path is redirected back along the frame. In addition, polyurethane foam is used to prevent global frame buckling and to contribute to energy absorption. The concept is tested experimentally as an 
improvement for hard surface impact; however, impact testing is encouraged to determine the equivalent performance onto water.

\section{Recommendations For Future Directions}

1. Accident surveys / crash investigations are an essential part of crashworthiness research, in order to provide feedback on structural response (and hence understanding of the failure mechanisms), and the effectiveness of proposed crashworthy measures.

2. The experimental and numerical results have demonstrated that water impact is a critical design scenario, where crash requirements from both hard and soft surfaces must be taken into account during the preliminary design phase. This issue has necessitated the redesign of frame, joint and outer skin constructions and led to concept validation of dual role capability subfloor structures that utilize the 'infinite' stroke offered by the water as a passive energy absorber.

3. The growth in the number of European funded research programmes has resulted in significant collaboration and technical exchange, enabling full-scale experimental programmes to be conducted to further understand water impact phenomena, together with the validation of predictive numerical techniques.

4. Collaboration between research institutions and industry is extremely important and has led to the sharing of expertise. One area that has seen significant development in the field of numerical methods is the application of coupled FE-SPH approaches to predict problems involving fluid-structure interaction.

5. Another growth area is the continued development of composite material models in order to provide a robust approach to modeling the complex failure modes exhibited by composites (crack formation, propagation and delamination). This area will 
continue to be important, due to increased use of composite materials in aircraft design. In addition, significant attention is also being given to the development of optimization methods (discrete and robust) for crashworthiness research.

6. Developing a next generation subfloor structure capable of providing improved crash protection in the event of an impact onto both hard and water surfaces is possible through frame / joint design, triggers and the use of composite and metallic materials.

\section{Concluding Remarks}

The future for crashworthiness development of helicopters impacting water has made considerable leaps in terms or proposed concepts, improved material models for failure and validated simulation methodologies, which will not only result in improved rotorcraft designs, but will have significant benefit to other areas of passenger crash protection.

The development of a local / global coupled numerical approach is important. Developing expertise in applying these methods to even more complex design regimes is necessary, if authorities are to accept virtual testing techniques for design concept development and certification.

It is envisaged that the use of discrete and robust optimization methods will be a fundamental part of future engineering research, not only in the area of structural design, but also in the field of crashworthiness. In addition, hybrid optimizers are also being developed that have the ability to switch from one search method (genetic algorithms, etc) to other gradient based search methods in order to rapidly search the design space for an optimum configuration. The future of crashworthiness research will lie in the exploration and development of these techniques, which will compliment existing numerical methods research. 


\section{References}

${ }^{1}$ Seddon, C.M., and Moatamedi, M. "Review of Water Entry with Applications to Aerospace Structures”, International Journal of Impact Engineering, Vol 32, (7), 2006, pp. 1045-1067.

${ }^{2}$ Von Karman, Th. “The Impact of Seaplane Floats during Landing”, NACA TN 321, 1929.

3"Military Standard, MIL-STD01210A, Light Fixed and Rotary Wing Aircraft Resistance”, Department of Defense, Washington DC, September, 1988

4"Aircraft Crash Survival Design Guide - Volume I - Design Criteria and Checklists”, USAAVSCOM TR 89-D-22A, Simula Inc., Phoenix, Az, Dec 1989.

5»Aircraft Crash Survival Design Guide - Volume II - Aircraft Design Crash Impact Conditions and Human Tolerance”, USAAVSCOM TR 89-D-22B, Simula Inc., Phoenix, Az, Dec 1989.

6”Aircraft Crash Survival Design Guide - Volume III - Aircraft Structural Crash Resistance”, USAAVSCOM TR 89-D-22C, Simula Inc., Phoenix, Az, Dec 1989.

7”Aircraft Crash Survival Design Guide - Volume IV - Aircraft Seats, Restraints, Litters and Cockpit / Cabin Delethalisation”, USAAVSCOM TR 89-D-22D, Simula Inc., Phoenix, Az, Dec 1989.

8”Aircraft Crash Survival Design Guide - Volume V - Aircraft Post Crash Survival”, USAAVSCOM TR 89-D-22E, Simula Inc., Phoenix, Az, Dec 1989.

9"Joint Service Specification Design Guide, Crew Systems Crash Protection Handbook”, JSSG-2010-7, 1998. 
${ }^{10}$ Coltman, J.W., and Neri, L.M., "Analysis of US Civil Rotorcraft Accidents for Development of Improved Design Criteria”, American Helicopter Society National Specialists' Meeting on Crashworthy Design of Rotorcraft, Atlanta, GA April 7-9, 1986.

${ }^{11}$ Coltman, J.W., Domzalski, L., and Arndt, S.M., "Evaluation of the Crash Environment for US Navy Helicopters......the Hazards and Navy Response”, American Helicopter Society National Specialists' Meeting on Crashworthy Design of Rotorcraft, Atlanta, GA April 7-9, 1986.

${ }^{12}$ Adams, B.H., "Acquisition and use of Data for Crashworthiness Improvements in US Army Helicopters”, American Helicopter Society National Specialists' Meeting on Crashworthy Design of Rotorcraft, Atlanta, GA April 7-9, 1986.

${ }^{13}$ Witllin, G., and Rapaport, M., "Naval Rotorcraft Water Impact Crash Simulation Using Program KRASH”, American Helicopter Society $49^{\text {th }}$ Annual Forum Proceedings, St. Louis, MO, May 19-21, 1993.

${ }^{14}$ Chen, C.C.T., Muller, M., and Fogary, K.M., "Rotorcraft Ditchings and Water Related Impacts that occurred from 1982 to 1989 - Phase I”, US Department of Transportation, FAA Technical Center, Atlantic City, DOT/FAA/CT-92/13, 1993.

${ }^{15}$ Muller, M., "Rotorcraft Ditchings and Water Related Impacts that occurred from 1982 to 1989 - Phase II”, US Department of Transportation, FAA Technical Center, Atlantic City, DOT/FAA/CT-92/14, 1993.

${ }^{16}$ Hughes, K., "Application of Improved Lagrangian Techniques to Helicopter Impacts on Water”, PhD Thesis, Cranfield University, 2005.

${ }^{17}$ Cronkhite, J.D., and Berry, V.L., “Crashworthy Airframe Design Concepts”, NASA CR 3603, 1982. 
${ }^{18}$ Berry, V.L., Cronkhite, J.D., and Mort, R.W., “Soil and Water Crash Impact Effects on Energy-Absorbing Structures”, U.S. Army AVSCOM Report No. 699-099-324, 1990.

${ }^{19}$ Pentecôte, N., and Vigliotti, A., "Simulation of the Impact on Water of a Subfloor Component and a Full Scale WG-30 Helicopter”, American Helicopter Society 58th Annual Forum Proceedings, Montréal, Canada, June 11-13, 2002.

${ }^{20}$ Hughes, K., Campbell, J., and Vigliotti, A., "Evaluation and Validation of a Typical Helicopter Subfloor Response to an Impact on Water using LS-DYNA3D”, $4^{\text {th }}$ International KRASH Users’ Seminar, Amsterdam, June, 2003.

${ }^{21}$ Vignjevic, R., Meo, M., “A New Concept for a Helicopter Subfloor Structure, Crashworthy in Impacts on Water and Rigid Surfaces”, International Journal of Crashworthiness, Vol. 7, (3), 2002, pp. 321-330.

${ }^{22}$ Ubels, L.C., and Wiggenraad, J.F.M., "Increasing the Survivability of Helicopter Accidents over Water”, First European Survivability Workshop, Cologne-Wahn, Germany, February 2002.

${ }^{23}$ Bisagni, C., “Crashworthiness of Helicopter Subfloor Structures”, International Journal of Impact Engineering, Vol. 27, (10), 2002, pp.1067-1082.

${ }^{24}$ Skinner, S., "Helicopter Sub-Floor Structure Crash Modeling - Rigid Wall and Water Impact”, MSc Thesis, Cranfield University, 2003.

${ }^{25}$ Pifko, A.B., and Winter, R., “Theory and Application of Finite Element Analysis to Structural Crash Simulation”, Computers and Structures, Vol. 13, (1-3), 1980, pp 277285.

${ }^{26}$ Pifko, A.B., Winter, R., and Ogilvie, P.L., “DYCAST - A Finite Element Program for the Crash Analysis of Structures”, NASA Contract Report - 4040, 1987 
${ }^{27}$ Michielsen, A.L.P.J., Wiggenraad, J.F.M., Ubels, L.C., and Frijns, R.H.W.M., “Design, Test and Analysis of Tensor Skin Panels for Improved Crashworthiness in Case of Water Impacts”, AHS Crashworthiness Specialists Meeting, Crash Safety Challenges and Innovative Solutions, Phoenix, Arizona, 1994

${ }^{28}$ Thuis, H.G.S.J., de Vries, H.P.J., and Wiggenraad, J.F.M., “Sub-Floor Skin Panels for Improved Crashworthiness of Helicopters in Case of Water Impacts”, American Helicopter Society 51st Annual Forum Proceedings, Ft. Worth, TX, May 9-11, 1995.

${ }^{29}$ Delatombe, E, Delsart, D., Johnson, A., and Kohlgrüber, D.F., “Composite Helicopter Crashworthiness”, 24 ${ }^{\text {th }}$ European Rotorcraft Forum, Marseille, France, September 15-17, 1998.

${ }^{30}$ Kindervater, C.M., “Aircraft and Helicopter Crashworthiness: Design and Simulation”, Crashworthiness of Transportation Systems: Structural Impact and Occupant Protection, edited by J.A.C. Ambrosio, Kluwer Academic Publisher, Netherlands, 1997, pp 525-577.

${ }^{31}$ Fleming, D.C., "Delamination Modeling of Composites for Improved Crash Analysis”, Journal of Composite Materials, Vol. 35, (19), 2001, pp.1777-1792.

${ }^{32}$ Sareen, A. K., Smith, M.R., and Hashish, E. 'Crash Analysis of an EnergyAbsorbing Subfloor during Ground and Water Impact', American Helicopter Society International 55th Annual Forum Proceedings, Montréal, Canada, May 25-27,1999

${ }^{33}$ Vicente, J.L.S., Beltran, F., and Martinez, F., "Simulation of Impact on Composite Fuselage Structures”, European Congress on Computational Methods in Applied Science and Engineering (ECOMAS), Barcelona, September 2000. 
${ }^{34}$ McCarthy, M.A., Wiggenraad, J.F.M., Kohlgrüber, D.F., and Kamoulakos, D., "Finite Element Modeling of Crash Response of Composite Aerospace Sub-Floor Structures”, Computational Mechanics, Vol. 26, (3), 2000, pp. 250-258.

${ }^{35}$ Deletombe, E., Delsart, D., Kohlgrüber, D., and Johnson, A.F., "Improvement of Numerical Methods for Crash Analysis in Future Composite Aircraft Design”, Aerospace Science and Technology, Vol. 4, (3), 2000, pp. 189-199.

${ }^{36}$ Kindervater, C.M., "Trends in Simulation - Helicopter and Aircraft Structures under Extreme Crash and High Velocity Impact”, American Helicopter Society $61^{\text {st }}$ Annual Forum Proceedings, Grapevine, TX, June 1- 3, 2005.

${ }^{37}$ Winter, R., Pifko, A.B., and Armen Jr, H., "Crash Simulation of Skin-Frame Structures using a Finite Element Code”, SAE paper 770484, 1977

${ }^{38}$ Vignjevic, R., and Calvancanti, M. J., "Numerical Simulation of the Lynx Helicopter Main Lift-frame Component Collapse”, International Journal of Crashworthiness, Vol. 2, (1), 1997, pp.25-38.

${ }^{39}$ DRI / KRASH 2006 User Manuals/ Theory; Volume 1-3, dated 31 ${ }^{\text {st }}$ December, 2006, Dynamic Response Inc., Developers of KRASH, http://www.dri-krash.com/

${ }^{40}$ Brite-Euram project, CRASURV: “Commercial Aircraft - Design for Crash Survivability”, CT96-0207, 1996-1999. (See Ref. 34 also)

${ }^{41}$ Wittlin, G., Smith, M., Sareen, A., and Richards, M., "Airframe Water Impact Analysis using a Combined MSC/MSC DYTRAN - DRI/KRASH approach”, American Helicopter Society 53rd Annual Forum Proceedings, Virginia Beach, VA, April 29-May 1, 1997. 
${ }^{42}$ Zorz, R., and Pozzato, L., "WG-30 Full Scale Simulation by DRI/K-RASH and Comparison with Test Results”, $4^{\text {th }}$ International KRASH User's Seminar, Amsterdam, June 2003.

${ }^{43}$ Clarke, C.W., and Shen, Y.C., "The Development of a Rotorcraft Water-Impact Analysis Methodology”, American Helicopter Society Crashworthiness Specialists Meeting on Crash Safety, Phoenix, Arizona, AZ, September 1-2, 1998.

${ }^{44}$ Ribet, H., Laborde, P., and Mahe, M., "Numerical Modeling of the Impact on Water of a Flexible Structure by Explicit Finite Element Method - Comparisons with Radioss Numerical Results and Experiments”, Aerospace Science and Technology, Volume 3, (2), 1999, pp.83-91.

${ }^{45}$ Vignjevic, R., and Meo, M., "Simulation of Helicopter Subfloor Structure Impact on Water”, International Journal of Crashworthiness, Vol. 6, (3), 2001, pp. 425-443.

${ }^{46}$ Vignjevic, R., De Vuyst, T., and Campbell, J., "The Use of a Homogeneous Repulsive Force for Contact Treatment in SPH", in H.A. Mang, F.G. Rammerstorfer, J. Eberhardsteiner Eds., WCCM V: Fifth World Congress on Computational Mechanics, Vienna, Austria, July 2002.

${ }^{47}$ Fasanella, E.L., Jackson, K.E., Lyle, K.H., Sparks, C.E., and Sareen, A. "MultiTerrain Impact Testing of a Composite Energy Absorbing Fuselage Section”, Journal of the American Helicopter Society, Vol. 52 (2), 2007, pp 159-168.

${ }^{48}$ Jackson, K.E., "Impact Testing and Simulation of a Crashworthy Composite Fuselage Concept”, International Journal of Crashworthiness, Vol. 6, (1), 2001, pp. 107121. 
${ }^{49}$ Randhawa, H.S., and Lankarani, H.M., "Finite Element Analysis of Impacts on Water and its Application to Helicopter Water Landing and Occupant Safety”, International Journal of Crashworthiness, Vol. 8, (2), 2003, pp. 189-200.

${ }^{50}$ Wittlin, G., Schultz, M., and Smith, M.R., "Rotary Wing Aircraft Water Impact Test and Analyses Correlation”, American Helicopter Society $56^{\text {th }}$ Annual Forum, Virginia Beach, VA, May 2-4, 2000.

${ }^{51}$ TASS - TNO Automotive Safety Solutions, Developers of MADYMO, http://www.tass-safe.com/cms/index.php - last accessed February 2008.

${ }^{52}$ Pentecôte, N., and Vigliotti, A., "Crashworthiness of Helicopters on Water: Test and Simulation of a Full-scale WG-30 Impacting on Water”, International Journal of Crashworthiness, Vol. 8, (6), 2003, pp. 559-572.

${ }^{53}$ Kohlgrüber, D., Vigliotti, A., Weissberg, V., and Bartosch, H., "Numerical Simulation of a Composite Helicopter Subfloor Structure Subjected to a Water Impact”, American Helicopter Society 60th Annual Forum, Baltimore, MD, June 2004.

${ }^{54}$ De Vuyst, T., “Hydrocode Modeling of Water Impact”, PhD Thesis, Cranfield University, 2003

${ }^{55}$ Kohlgrüber, D., Pentecôte , N., Vigliotti, A., Bartosch, H., and Weissberg, V., "FEAnalyses of Water Impact Tests on Helicopter Structures”, $4^{\text {th }}$ International KRASH User’s Seminar, Amsterdam, June 2003.

${ }^{56}$ Vignjevic, R., “SAFESA - Safe Structural Analysis, Technical Note on Detailed Assessment”, DTI/SERC Project 9034, Cranfield University.

${ }^{57}$ Hughes, K., and Vignjevic, R., “Application of the Finite Element Method for Developing Helicopter Crashworthiness for Impacts on Water: Implications for Virtual 
Testing”, Presented at the Royal Aeronautical Society Conference on Virtual Testing, London, October 2006.

${ }^{58}$ Zardoni, L., "Cavitation Modeling in DYNA3D”, MSc Thesis, Cranfield University, 2005

${ }^{59}$ Candy, E.G., Kirk, N.E., and Murrell, P.J., “Airframe Water Impact Analysis”, International Journal of Crashworthiness, Vol. 5, (1), 2000, pp.51-62.

${ }^{60}$ Air Accident Investigation Branch, "Report on the Accident to Sikorski SG1N, GBTWL at Brent Spar, East Shetland Basin on 25 July, 1990”, AAIB Report 2/91, UK

61, Crashworthiness for Commercial Aircraft”, $3^{\text {rd }}$ European Framework Programme, Brite-Euram Project IMT Area 3 Aeronautics: AERO-CT92-0030, 1993-1995.

${ }^{62}$ Hessmer, U., "HeliSafe - EU Research into Occupant Safety in Helicopter Crashes”, Air and Space Europe, Volume 3, (3-4), 2001, pp. 225-227.

${ }^{63}$ Fasanella, E.L., Jackson, K.E., and Lyle, K.H., "Finite Element Simulation of a Full Scale Crash Test of a Composite Helicopter”, American Helicopter Society $56^{\text {th }}$ Annual Forum Proceedings, Virginia Beach, VA, May 2-4, 2000.

${ }^{64 "}$ CAST - Crashworthiness of Helicopters onto Water - Design of Structures using Advanced Simulation Tools", funded by the European Community under the “Competitive and Sustainable Growth” Programme (Contract G4RD-CT1999-0172), 2000-2003

${ }^{65}$ De Vuyst, T., Vignjevic, R., and Campbell, J., “Coupled FE-SPH Modeling of Fluid Structure Interaction”, $4^{\text {th }}$ International KRASH Users' Seminar, Amsterdam, June 2003. 
${ }^{66}$ CRAHVI - Crashworthiness of Aircraft for High Velocity Impact” funded by the European Community under the "Competitive and sustainable Growth" programme (Contract G4RD-CT-2000-00395), 2001-2004.

${ }^{67}$ Civil Aviation Authority, "Crashworthiness of Helicopter Floatation Systems", Civil Aviation Authority Contact Report, 2001-2002.

${ }^{68}$ Jackson, K.E., and Fasanella, E.L., "Development of a 1/5 Scale Model Fuselage Concept for Improved Crashworthiness”, Symposium on Size Effects and Scaling Laws, 13th US National Congress on Applied Mechanics, Gainesville, FL, June 1998.

${ }^{69}$ Jackson, K.E., and Fasanella, E.L., “Crashworthy Evaluation of a 1/5-Scale Model Composite Fuselage Concept”, NASA TM 209132, 1999.

${ }^{70}$ Jackson, K.E., and Fasanella, E.L., "Impact Testing and Simulation of a Crashworthy Composite Fuselage”, American Helicopter Society $56^{\text {th }}$ Annual Forum Proceedings, Virginia Beach, Virginia, VA, May 2-4, 2000.

${ }^{71}$ Fasanella, E.L., Jackson, K.E., and Lyle, K.H., "Finite Element Simulation of a Full-scale Crash Test of a Composite Helicopter”, American Helicopter Society 56th Annual Forum Proceedings, Virginia Beach, Virginia, VA, May 2-4, 2000.

${ }^{72}$ Sareen, A.K., Fasanella, E.L., Sparks, C., Jackson, K.L., and Mullins, B.R., "Comparison of Hard Surface and Soft Soil Impact Performance of a Crashworthy Composite Fuselage Concept”, American Helicopter Society 58th Annual Forum Proceedings, Montreal, Canada, June 11-13, 2002.

${ }^{73}$ Fasanella, E.L., and Jackson, K.E., "Impact Testing and Simulation of a Crashworthy Composite Fuselage Section with Energy-Absorbing Seats and Dummies”, NASA TM 211731, 2002. 
${ }^{74} J a c k s o n$, K.E., Fasanella, E.L., and Boitnott, R., “Occupant Responses in a FullScale Crash Test of the Sikorsky ACAP Helicopter”, American Helicopter Society 58th Annual Forum Proceedings, Montreal, Canada, June 11-13, 2002.

${ }^{75}$ Jackson, K.E., Fasanella, E.L., Boitnott, R.L., and Lyle, K.H., "Full-Scale Crash Test and Finite Element Simulation of a Composite Prototype Helicopter”, NASA TP2003-212641, ARL-TR-2824, August 2003.

${ }^{76}$ Fasanella, E.L., and Jackson, K.E., "Best Practices for Crash Modeling and Simulation”, NASA TM 211944, October 2002.

${ }^{77}$ Vigliotti, A., Pentecôte, N., and Clifford, S., "Crashworthiness of Rotorcraft on Water: an Experimental Test Campaign”, 28 ${ }^{\text {th }}$ European Rotorcraft Forum, Bristol, England, September 2002.

${ }^{78}$ Perez-garijo, G., "Simulation of a Composite Helicopter Subfloor Impact on Water”, MSc Thesis, Cranfield University, 2004.

${ }^{79}$ Tho, C-H, Sparks, C.E., Sareen A.K., "Hard Surface and Water Impact Simulations of Two Helicopter Subfloor Concepts”, American Helicopter Society $60^{\text {th }}$ Annual Forum, Baltimore, MD, June 2004.

${ }^{80}$ Lanzi, L., Bisagni, C., and Ricci, S., "Neural Network Systems to Reproduce Crash Behavior of Structural Components”, Computers and Structures, Vol. 82, 2004, pp. 93108.

${ }^{81}$ Vignjevic. R., Campbell, J., Hughes, K., Lukyanov, A., and Reveles, J., "Recent Advances in the Development of Helicopter Crashworthiness for Impact on Water", $32^{\text {nd }}$ European Rotorcraft Forum, Maastricht, September 2006 
${ }^{82}$ De Vuyst, T., Vignjevic, R., and Campbell, J., “Coupling between Meshless and Finite Element Methods”, International Journal of Impact Engineering, Vol 31, (8), 2005, pp 1054-1064.

${ }^{83}$ Vignjevic, R., De Vuyst, T., and Campbell, J., “A Frictionless Contact Algorithm for Meshless Methods”, Computer Modeling in Engineering \& Sciences, Vol. 13, (1), 2006, pp. 35-48.

${ }^{84}$ Taher, S.T., Mahdi, E., Mokhtar, A.S., Magid, D.L., Ahmadun, F.R., and Arora, P.R., “A New Composite Energy Absorbing System for Aircraft and Helicopter”, Composite Structures, Vol. 75, 2006, pp. 14-23. 


\section{List of Figures}
(a) Hard surface impact
(b) Water surface impact

1. The difference in response of a conventional metallic subfloor design to two different extremes in loading. ...

2. Overview of the post-test response for a metallic subfloor dropped at $8 \mathrm{~ms}^{-1}$ as part of the CAST project. Photographs courtesy of CIRA, Italy (Ref. 20)

3. Comparison between post-test and LS-DYNA3D simulation results for an $8 \mathrm{~ms}^{-1}$ water drop test of a component floor, performed as part of the CAST project (Ref. 16).

4. Comparison between post-test and LS-DYNA3D simulation results for an $8 \mathrm{~ms}^{-1}$ water drop test of a full-scale WG-30 helicopter, performed as part of the CAST

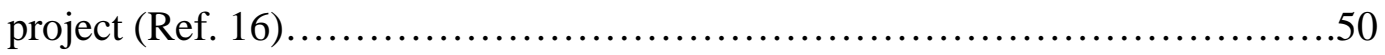

5. The composite demonstrator that was developed as part of the European CAST project (Ref. 53 and Ref. 64).

6. Pam-Crash simulation of the composite demonstrator developed as part of the CAST project for an $8 \mathrm{~ms}^{-1}$ impact onto water (Ref. 53).... 


\section{List of Tables}

1. Typical helicopter structural damage encountered during a vertical, level water

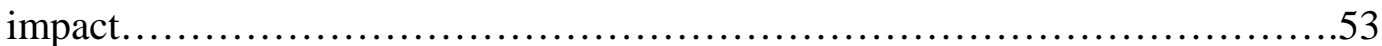




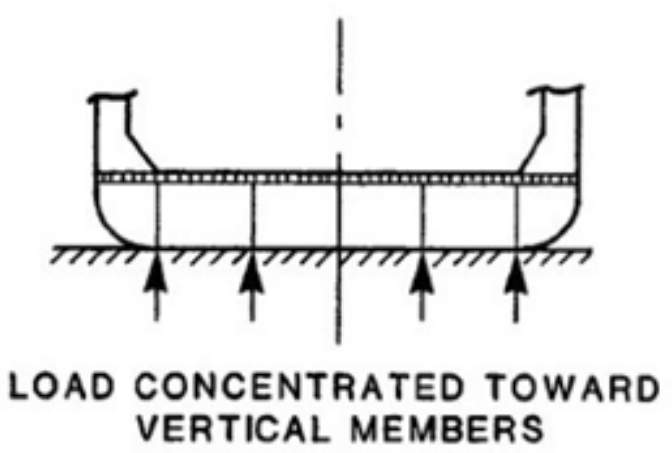

(b) Hard surface impact

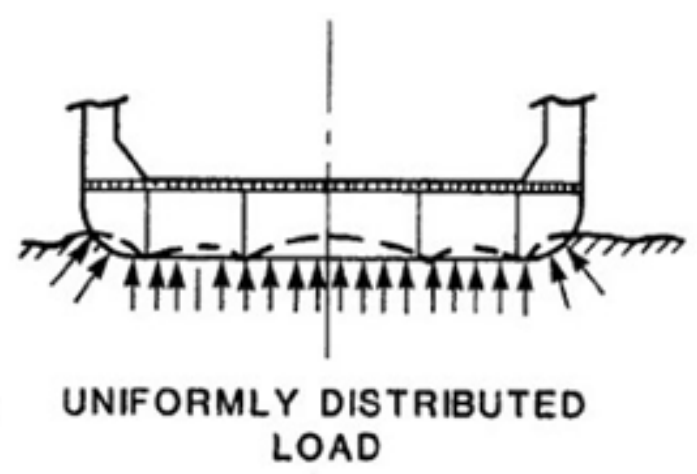

(b) Water surface impact

Fig. 1. The difference in response of a conventional metallic subfloor design to two different extremes in loading 

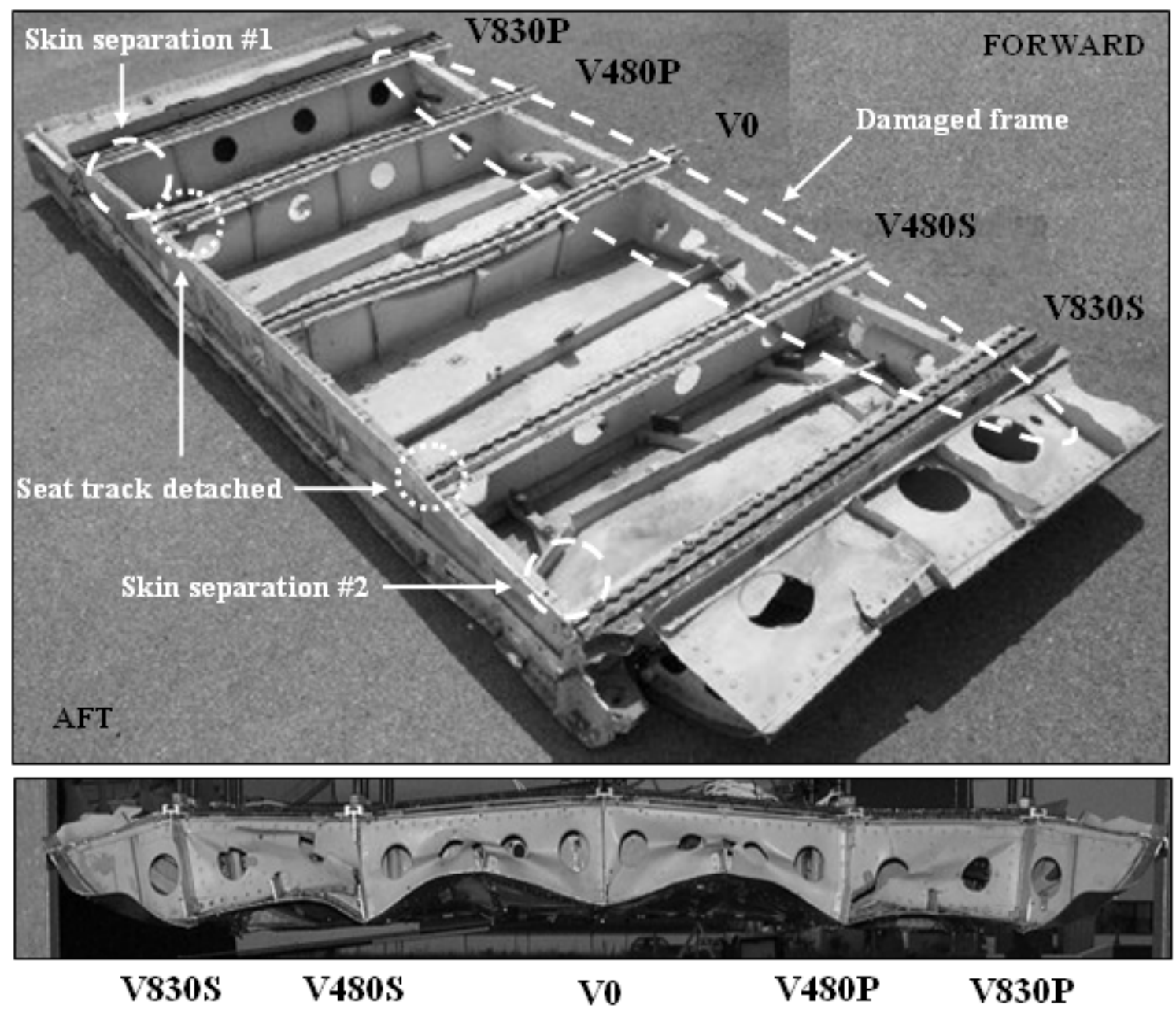

Fig. 2. Overview of the post-test response for a metallic subfloor dropped at $8 \mathrm{~ms}^{-1}$ as part of the CAST project. Photographs courtesy of CIRA, Italy (Ref. 20) 

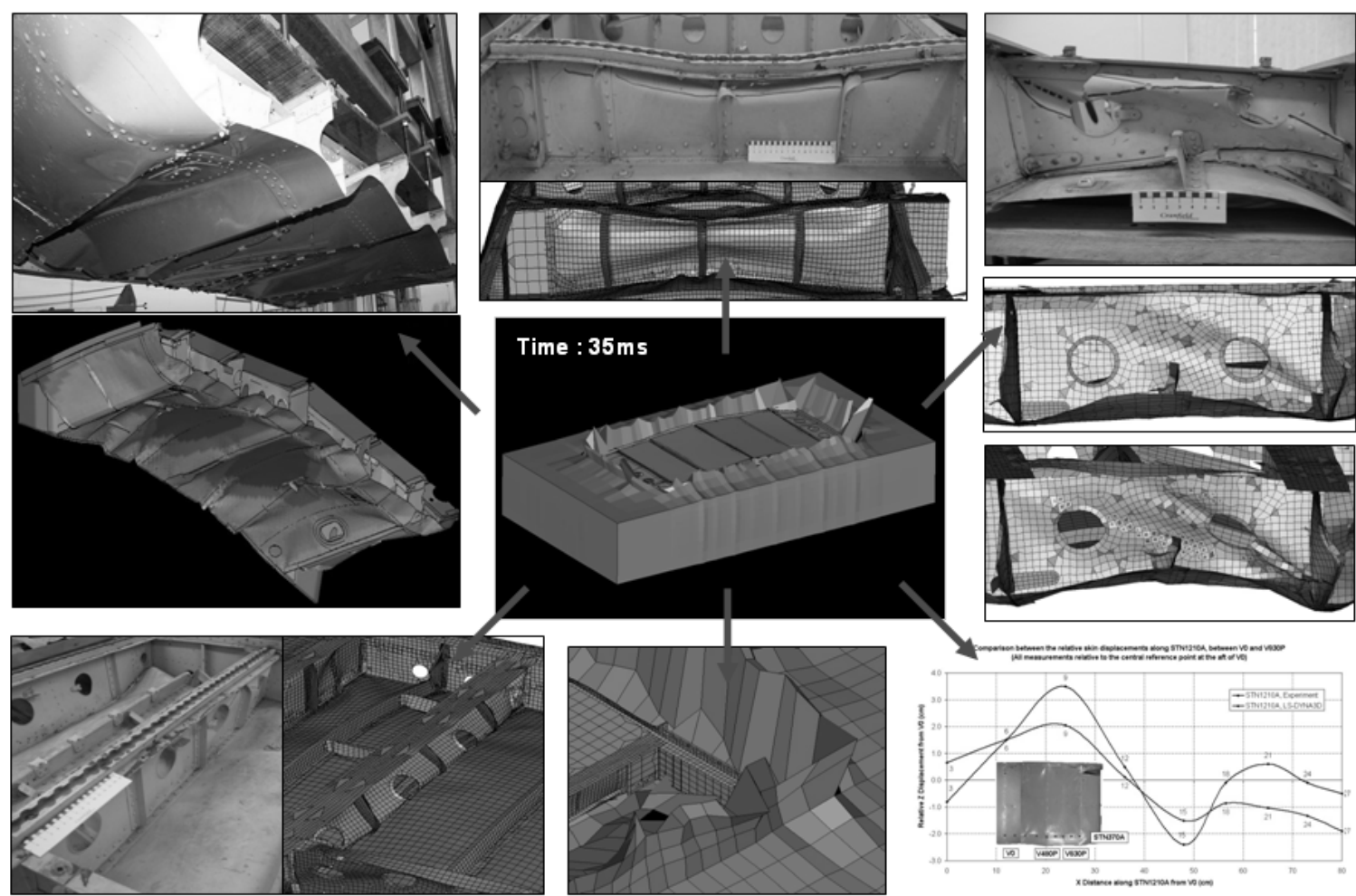

Time : $35 \mathrm{~ms}$
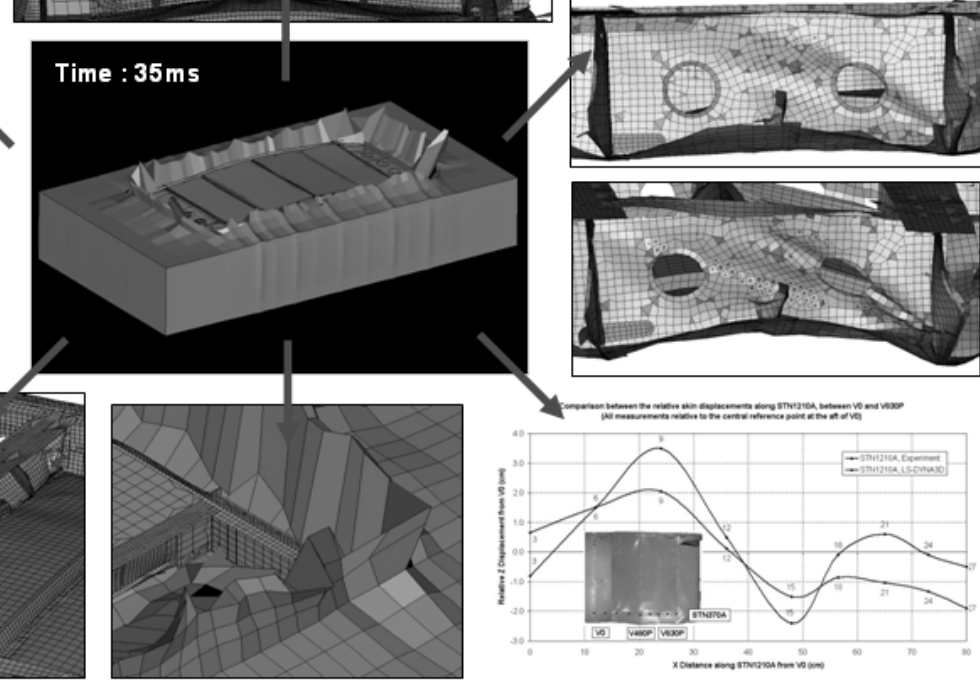

Fig. 3. Comparison between post-test and LS-DYNA3D simulation results for an $8 \mathrm{~ms}^{-1}$ water drop test of a component floor, performed as part of the CAST project (Ref. 16) 


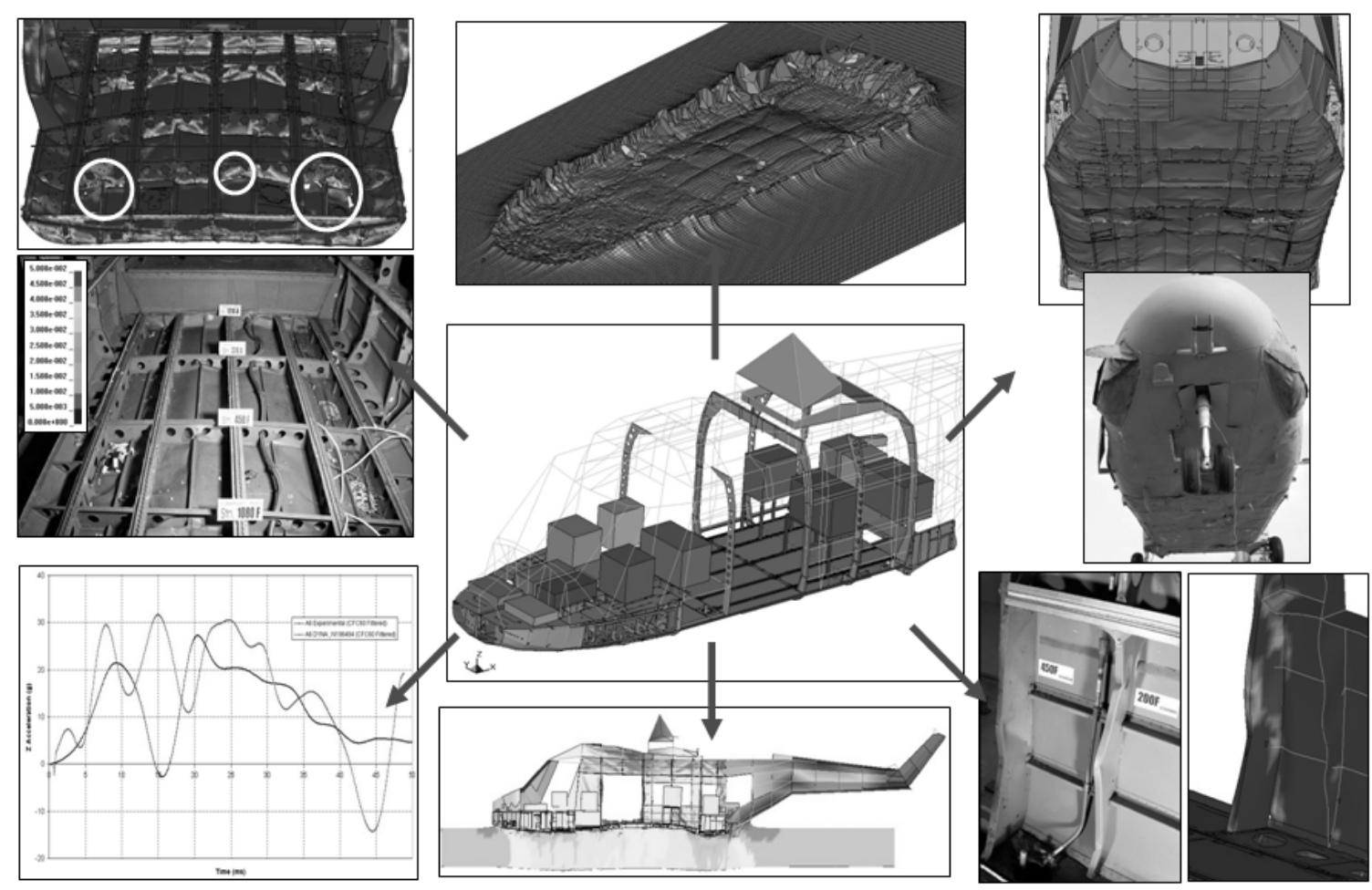

Full-scale : $363 \mathrm{~K}$ shells, $5.2 \mathrm{~K}$ beams, $5.7 \mathrm{~K}$ rivets, $228 \mathrm{~K}$ solids, $5.7 \mathrm{~K}$ rivets

Fig. 4. Comparison between post-test and LS-DYNA3D simulation results for an $8 \mathrm{~ms}^{-1}$ water drop test of a full-scale WG-30 helicopter, performed as part of the CAST project (Ref. 16) 


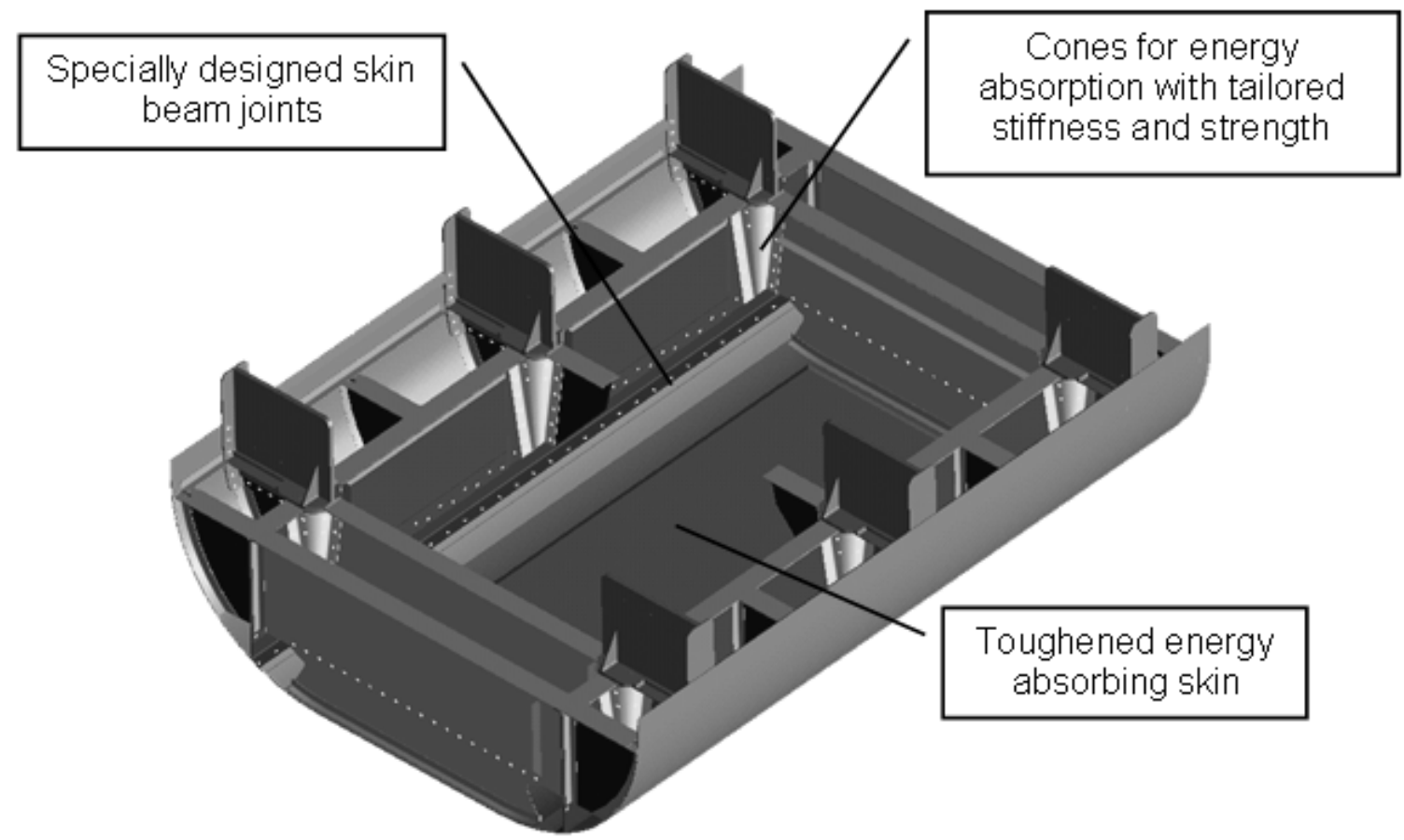

Fig. 5. The composite demonstrator that was developed as part of the European CAST project (Ref. 53 and Ref. 64) 

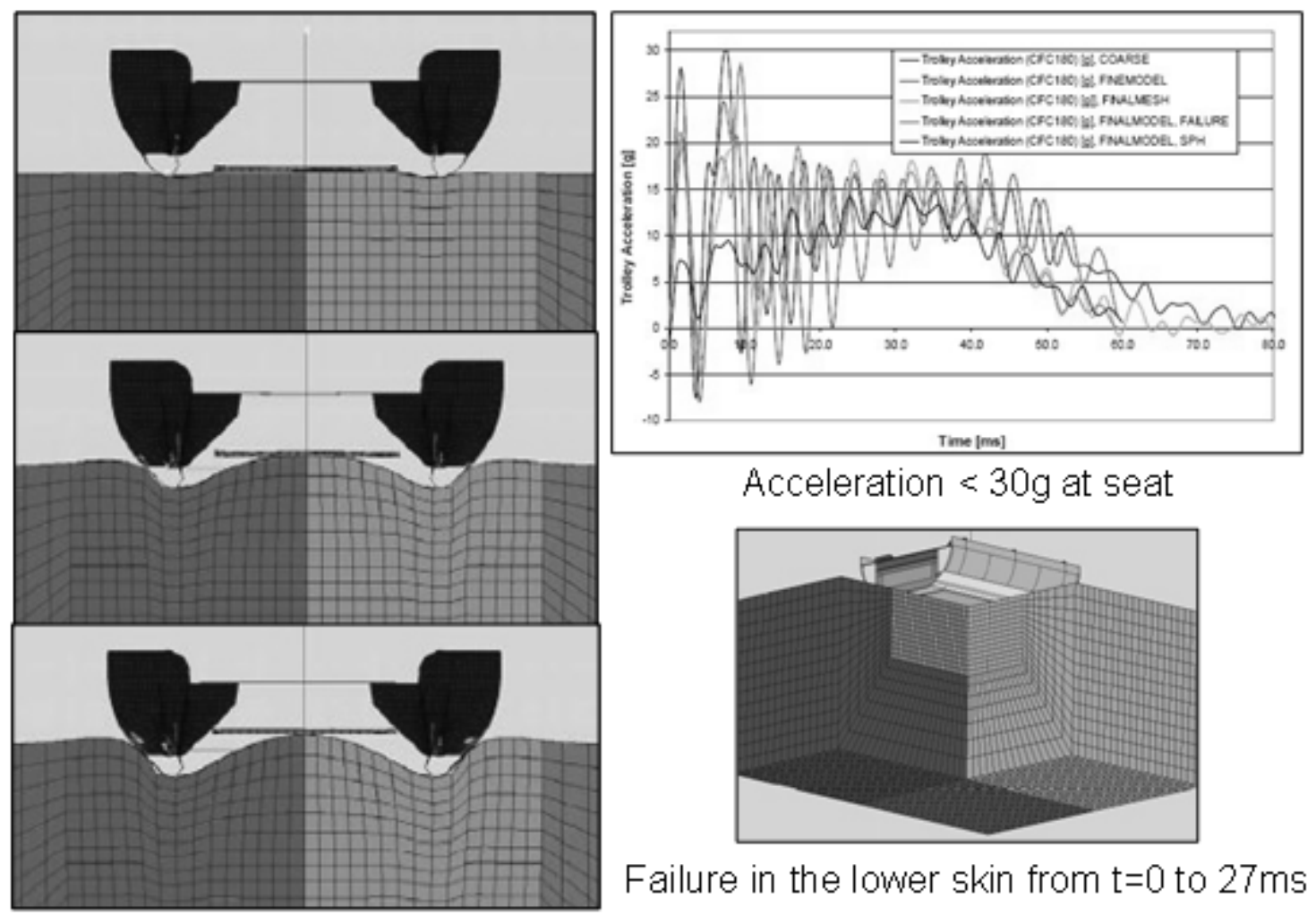

Acceleration $<30 \mathrm{~g}$ at seat

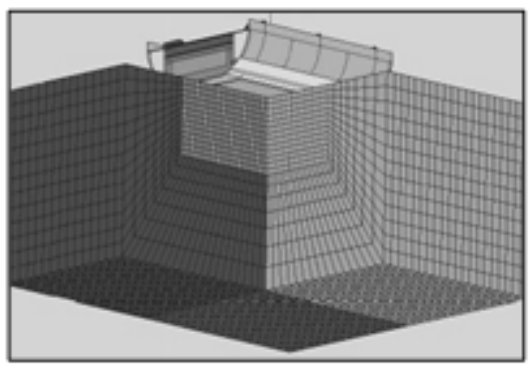

Failure in the lower skin from $t=0$ to $27 \mathrm{~ms}$

Fig. 6. Pam-Crash simulation of the composite demonstrator developed as part of the CAST project for an $8 \mathrm{~ms}^{-1}$ impact onto water (Ref. 53) 
Table 1. Typical helicopter structural damage encountered during a vertical, level water impact

Typical structural damage encountered during an impact on water

Extensive skin damage / panel loss

Reduced floatation

Extensive material / rivet failure

Tail boom separation

Jamming / door attachment

Cabin floor damaged / distorted

Displacement of roof

Lift frame deformation

Seat distortion / detachment

Destruction of windows / windshield

Fuselage failure (distortion, separation) 